\title{
PROFESSIONAL DEVELOPMENT TUTORING: COMPARING ITALIAN AND INTERNATIONAL MODELS
}

\author{
Alessandra Romano (University of Siena) ${ }^{\star}$
}

\begin{abstract}
The paper presents the first outcomes of a comparative research of the incoming, on-going and outgoing practices of tutorship. The purposeful sample of universities extracted consisted of 18 Italian universities and 18 US universities. A tutorship concept in line with the transversal cross-curricular skills required for undergraduate and graduate students (Green Paper 2016, Dublin descriptors 2004) exceeds the vision of assistential tutorship and student tutoring practices, exercised by teachers and/or offered by services devoted to different types of intervention. The tutorship can be conceived as systemic and organizational action coherent in all phases with professionalising approach, starting from the earliest initiatives between school and university classrooms.
\end{abstract}

KEYwORDs: tutorship, soft-skills, work-oriented approach, comparative study, best practices.

\section{Introduction}

Universities are making efforts to build and strengthen close ties with businesses, and country's productive sectors, to catch up with emerging and challenging learning needs with respect to current job scenarios and dialogue with stakeholders (Fabbri, Melacarne 2016: 320).

The Department of Education, Humanities and Intercultural Communication at the University of Siena promoted profound transformations in the last decade (Fabbri, Melacarne 2016). The diffused instances of innovation in university teaching testify the crisis of a teaching model lesson-centered. The training of professionals who have skills not only tied to knowing, but also to knowing how to do and how to stay in contexts, are recognized as paradigms that are now located in the university mission. The ongoing changes privileged multidisciplinary approaches to research and teaching, paying close attention to relationships with multi-stakeholder belonging to the enterprises and business labor market by involving them from the beginning in the redesign of more and more professional graduate courses.

* Alessandra Romano, PhD Researcher of General Didactics and Special Education, Department of Scienze della formazione, scienze umane e della comunicazione interculturale, University of Siena, Italy. Email: alessandra.romano2@unisi.it.

V. Boffo, M. Fedeli (edited by), Employability \& Competences. Innovative Curricula for New Professions, () 2018 Author(s), content CC BY-SA 4.0 International, metadata CC0 1.0 Universal, published by Firenze University Press (www.fupress.com), ISSN 2704-5781 (online), ISBN 978-88-6453-672-9 (online PDF), ISBN 978-88-9273-119-6 (XML), 


\section{The context of the research}

In this institutional framework, the Department of Education, Humanities and Intercultural Communication needs to face a challenging problem: the data on the latest cohorts of students enrolled in the three-year Bachelor degree programs in Education and Training Sciences (cohorts 2013-14, 2014-2015 and 2015-2016) showed a percentage of around $20 \%$ of formal study abandonment and dropout, a percentage of $48 \%$ of regularly graduated students, about $10 \%$ of students being suspended for non-paying university fees, and a percentage of around $20 \%$ of students registered but that didn't pass all the exams.

\subsection{The actions of the Tutorship Committee}

An elective group of teachers meets forming the Department's Tutorship Commission. The framework of community of practice building (Wenger, McDermott, Snyder 2007) helps to conceptualize and offers interpretative lens to read the processes of the aggregation and management of the Commission. The members of the community of the Department Commission share patterns, protocols, languages and follow a common purpose. The common interest is to address the problem of the abandonments and of the so-called 'suspensions' of university careers to counteract the delays in the university success and the phenomena of drop-out. The numbers provided represented a disorienting dilemma (Mezirow 2003) for the department, so the commission has been questioning how to make the Degree in Education Sciences more attractive and more distinguished from the viewpoint of the profession practices and actions, in order to support the academic careers and perfomances of students. In addition to this, there is a question of methodological order: how to study actions in transformative practice systems and trajectories that involve and engage key stakeholders (students, faculty, departmental governance)?

Faced with these problems, the community of teachers, as researchers interested in the educational issues, chooses to start an inquiry process aimed at making decisions, solving problems and supporting transformative trajectories.

The recurrence of the phenomenon in the three cohorts examined elicited some reflections: it was not possible to consider the problem as an individual question, but it was understandable under the socially distributed, collective and organizational dimensions of the department as educational organization. How to themathize the issue of students' drop-out in terms of organizational learning? Paparella at this regard (2009) writes: 
An organization that learns creates proactively, acquires and transfers knowledge and changes its behavior on the basis of new knowledge and new suggestions. Learning organizations actively try to infuse new ideas and information. To do this, they look closely at the outdoor environments, take on the new talents and experts they need and invest important resources in the training and development of their collaborators. Subsequently, the new knowledge created must be transmitted to the whole organization. Learning organizations are committed to reducing structural, procedural and interpersonal factors that hinder the sharing of information, ideas and knowledge among members of the organization. Behavior must also change as a result of a new way of learning (Paparella 2009: 176).

The first mandate of the research resulted in the activation of an exploratory-euristic route designed to accompany expert systems of teachers-tutors, carriers of implicit and explicit knowledge, in a process of co-production and sharing of knowledge.

The research group accepts the task to search and to collect examples and extracts of tutoring practices (a) to create a literature of examples that could also encode mainstream trends, (b) to accompany a professional community towards the construction and sharing of a common repertoire of good tutorship practices.

The need to bring new elements to the scripts shared between tutors and students in the community of the department, the need to improve the tutoring services offered, and to unpack tutorship practices in more differentiated segments and specific, has pushed the commission in the field of new investigative trails. How to deal with good practice in national and international universities? How to deal with diverging, challenging, non-familiar models to open to the issue of students' drop-out? How to develop systems action to face students' careers abandonment?

The comparative research on the tutorship practices draws out from these research questions.

\section{Comparing good practices and non-family models}

In the first step of the comparative study, in-coming, on-going and outgoing tutorship practices are investigated through documental analysis using online information and documentation sources. The first bottom-up categorization of the tutorship practices distinguishes six different branchs:

1. tutoring between peers, organizational actors and stakeholders/ mentors;

2. peer-tutoring practices; 
3. didactic tutorship;

4. tutorship for specific services (disability, information);

5. professional/vocational tutoring;

6. information tutoring.

18 Italian universities and 18 European and US universities were selected. The selection criteria for universities were:

a. geopolitics (North, Center, South Italy) ${ }^{1}$

b. greatness (small, medium and large universities) ${ }^{2}$

c. state, public and private

d. traditional and telematic (online and blended tutoring systems)

The focus was on tutorship practices which the universities have put in place the policies for promoting the employability and acquisition of soft-skills (Boffo 2017). The data analysis allows to craete an ad hoc modeling on the Rahin model to explore customization and personalization of diversified tutoring practices according to the categorizations indicated.

The goal was not to develop a theory of tutorship systems, the 'winning formula' for the most attractive university, but to describe tutorship practices in academic communities. The choice of researchers was to contribute to highlighting some aspects of 'family resemblance' (Fabbri 2007) between various tutorship activity systems. The purpose was to define a formal modeling that enables to capture the processuality and the potential impact of the tutorship in the academic training path, especially in preventing drop-out phenomena.

\subsection{Comparative analysis of the existing: the normative references}

The tutorship system is part of the Student Support Services at the University (Law No. 19, 1990, No.341, Article 13). The Tutor is an effective means to support university teaching as can act as (a) mediator between students and the university demanding tasks, (b) supervisor and (c) facilitator in communication and learning (Article 13 of Law 341/1990).

${ }^{1}$ About the geopolitic division, the reader may see the ISTAT protocols: $<$ http:// www3.istat.it/strumenti/definizioni/comuni/ripartizioni_regioni_province.csv $>$ (01/2018).

${ }^{2}$ the division of the universities according to their greatness was developed on the basis of the statistic data released by MIUR, about the students registrations with the update of the last academic year (2014/2015). The data are available at <http://statistica. miur.it/scripts/IU/vIU0_bis.asp> (03/2018). Based on the available data, a categorization has been performed on the basis of the absolute number of students enrolled, dividing the sample: the first third has been highlighted as BIG (B), the second third has been highlighted as Medium size (M), the last Third has been highlighted as Small (S). 
There are different ratings for tutorship practices. Lázaro (1997) formalizes four types of university tutoring (bureaucratic functional, academic, personal consultant and didactic). Zabalza (2003) speaks of three different levels of tutorship in the light of the objectives pursued:

1. the level of teacher function;

2. the level where tutorship provides advice on study skills or work systems;

3. the level where distance learning is provided, with job monitoring and job experience, etc. Álvarez and González (2008) proposed three major models of university tutoring (academic tutoring, didactic tutoring and service tutoring). According to this latter classification, academic tutoring is done in the classroom or in groups for each of the subjects taught by the faculty. It takes place at the classroom level and aims to improve students learning. The didactic tutoring is aimed at students from the enrollement to the end of the course. The Services tutorship is generally carried out by university service technicians who provide technical advice to students on issues related to their training (scholarships, mobility, transportation, housing, legal advice, etc.).

The tutorship model follows the prospect of holistic and continuous training, as proposed by the European Convergence Model (Álvarez, González 2008; Coriat, Sanz 2005). The tutorship course consists of transversal activity, it is not tied to a single subject. It is programmed and longitudinal, throughout all the course of the study, and aims to provide students with support for decision making and organizing their own "Training and professional project".

4. 'The rector who greets families': comparing models and practices of tutoring in comparison

The comparative analysis of tutorship practices requires first of all a work of disambiguation: often similar tutorship practices have many contact points but different denominations.

Sometimes the same label is used in different contexts to describe different services. Orientation services aimed at attracting new students at their university, showed the educational and organizational structures of the university, underlining why potential clients-students had to choose that university.

The in-coming tutorship is commonly performed in those ways (present in 32/36 universities):

- Open Day: In these 'open doors' days, the university shows its own structures and training plans of all the degrees programs. The tutors 
often are required to work in front office and accompanying potential students through guided tours. Most universities repeat the presence of teachers at the presentation of the courses and oft he degree programs.

- Test Lesson: Potential students are involved in lesson for showing the most concrete aspects of university education through open lessons and laboratory sessions.

- Connections with high schools: universities hold contact with local schools in two ways, (a) proposing open workshops where university activities are presented and (b) hosting high school students in conferences and activities ad hoc.

The most emerging promising practices are:

- Online platforms and self-evaluating questionnaires: With these tools, the potential students are able to navigate and learn about university activities and make a self-assessment of their attitudes by addressing university choice.

- Operative consultancy: special tutors (often tutor and guidance staff personnel) develop an orientation profile for the future students in the degree course most adhering to their knowledge and skills.

- Presentation of current students: this activity, which is frequent in the case of private universities, involves tutor students considered experts who have their own university experience.

- Skills balance and students competences portfolio.

In private universities, the families of the matriculates take part into the open days and the inauguration day of the academic year. The example of Ivy League American universities is paradigmatic: rectors meet matriculates' parents personally, welcoming them as participating members of the academic community. The rite is repeated at the graduation ceremony when the rector hosts the families of graduates and thank them and congratulate them on the achievement. These are marketing strategies that promote the development of sense of participation in students and families. In the contexts of American campuses, where students space out of the home, parental guidance becomes a supportive practice in the experience of transition that involves the entire family system.

\section{First emerging results}

The activities of the various levels of tutorship (incoming, on-going and out-going) are managed autonomously and decentralized by departments in universities sized as large and medium (Fig. 1). 
Figure 1 - Diagram of tutoring path from School to Job. [Source: author's own]

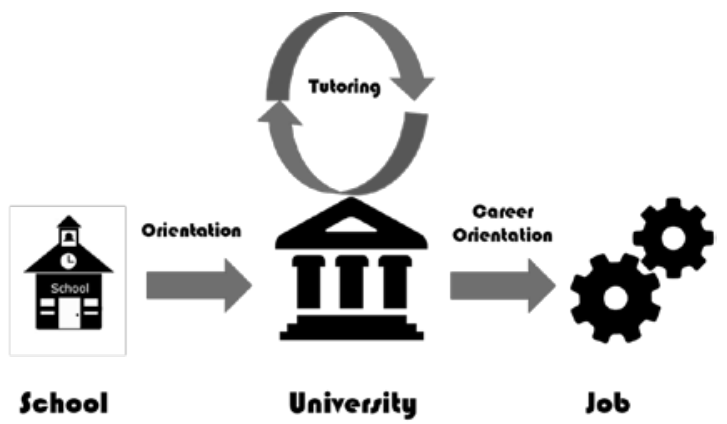

In the case of the ongoing tutorship, the major sections are three:

1. Didactic tutoring (support, individual, group),

2. Disability Services,

3. Counseling and Psychological Assistance.

The first activity is generally assigned to the support tutor, which is a continuation of the incoming tutoring (orientation) and helps students to orient themselves in the organizational didactic plans and in the creation of individual study plans. The support tutor helps also students in the logistics organization and in the retrieval of information and materials necessary for access to courses.

Didactic tutoring services used to manage students' requests individually, through appointments (often organized online) or in groups.

In all universities examined (36/36), the student tutoring is always attributed to the availability of teaching support services for students with disabilities and/or specific learning disabilities. In this case, the activities are mostly related to the logistic issues and are finalized to make the campus and its spaces 'accessible'. Through this service, the conditions of equal opportunities needed to enhance the autonomy of students with disabilities and to ensure their active participation in university life are promoted. Psychological counseling coincides with teaching tutoring and is designed to ensure students' well-being and prevent drop-out by providing tangible support. Psychological Counseling services have a higher percentage presence in public universities, less in private ones. In telematic universities, counseling meetings, of individual nature, have the task of intercepting those troublesome moments during university careers to prevent students' drop out.

Career counseling takes place in the last period of academic career, creating a link between student and job market. The people who manage these tasks are in most cases centers for job placement. 
The services are:

- Career Day: Days in which companies are presented to graduates and at the same time they can interact with stakeholders and business actors by proposing themselves as candidates and understanding the profiles required by companies. In these events, the participation of former students is marginal while the administrative offices manage the organization.

- Job Guidance Services: this service is offered in different branchs: $\mathrm{CV}$ and resume writing assistance, teaching strategies for interview management, specific consultations to determine the winning profile for hiring. In highly professional services, personalized consulting is proposed and human resource stakeholders are involved. The aim is to match the job offer with the job requests.

- Placement Office and Platforms for Job Vacancies and CVs building: These online services have virtual desks in which both those who are looking for new graduates and those who have completed a degree and aspire to a job can publish.

The Career Orientation Trails are divided into two moments:

- a group work in which the participants collaborate for decision making - an individual interview with the facilitators to explore some aspects related to attitudes in order to trigger more informed professional choices.

Lastly, business presentations are organized to have the specific time to meet the actors of the industry companies, such as Investment Bank Weekends and Recruiting Dates. The tutoring is stimulated through the participation of peer tutors (such as brilliant alumni and neo-graduates), as in the American model. We can itemize: technical-administrative services in specific offices, services involving exstudents, and counseling coaching. In particular, there are tutorings that work both in groups and through interviews with the tutors, experiential methods are adopted in presence and in virtual environments by working on real case studies or simulation architectures.

Informative tutoring is a type of cross-service across the all the fields, as it is provided at all levels by the offices of the various universities. Obviously it has a more pronounced feature in the case of the orientation where the request for information orients the inclusion of students in the university.

In the following picture they were represented by the diagrams of Eulero-Venn's own semantics, the mingling of the tutoring practices in the three bands: 1) orientation and in-coming tutorship, 2) on-going tutoring, 3) outgoing tutoring (career counseling) (Fig. 2). 
Figure 2 - Eulero-Venn Diagram for a mapping of Tutoring practices. [Source: author's own]

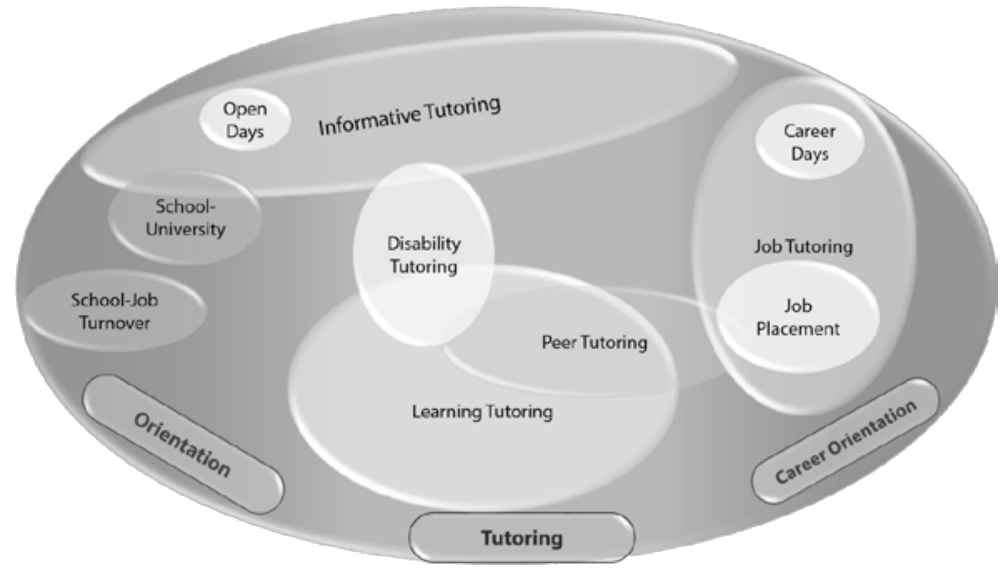

Regarding digitization of student and didactic services, tutoring with E-Learning platforms is widespread in both public universities and private universities. The massive use of MOOC and MOODLE platforms facilitates familiarization of students with technological devices through access to the information via video meeting or skype. This kind of service is typical of universities with great dimension or otherwise with a telematics nature. In telematic universities, the tutor, often called E-Tutor, has the task of supporting the student, fluidifying the learning process and assisting students.

Less used is the Summer Week, imported by the American model, which represents events in which future students can immerse themselves in culture and university mechanisms. Compared to the geographic location, the Northern Universities seem to have well structured tutoring systems based on peer tutoring, with extensive student attendance, while Southern Universities centralize this task on Orientation and Tutor Offices.

Regarding to internationalization and welcoming to foreign students, the analysed universities have services to facilitate the inclusion of international students. In most cases these services are provided by specific university offices, through technical-administrative staff.

\section{Modelling the tutoring practices}

Based on this comparative study I propose a conceptual model for describing tutoring practices. The conceptual model is borrowed from Rahim's model for negotiation and leadership profiles. 
The two parameters identified for the categorization of tutoring practices are:

1. Customization, which expresses the property of being designed according to the characteristics of the single user;

2. Individualization, which expresses the property of being designed to be available to all applicants.

The two dimensions are related to the characterization of tutoring practices. If a service is both personalized, and then perfectly tailored to meet the needs of the individual student and at the same time is highly individualized, that is, it is provided to all students as individuals, we talk about efficient service.

In the case of a little personalized and little individualized service we call it as a generalized service.

If the service or the practice is highly personalized, but weakly individualized is defined as customized service. If it is in the opposite quarter, it has a high degree of individualization and is therefore spread (Fig. 3).

Figure 3 - Model of tutoring practices. [Source: author's own]

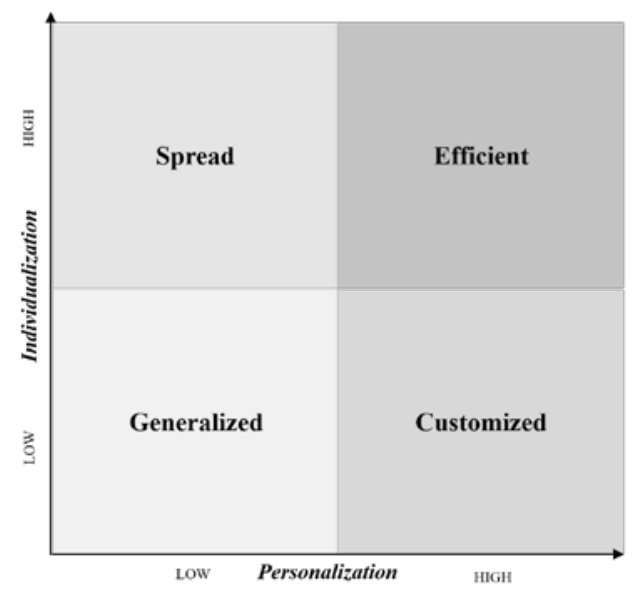

The proposed model allows to identify the most effective problem-based tutoring practices.

For the orientation services: the School-University Joint services and the active connections with the parents are highly customized and individualized practices, while activities such as Summer Week and door-to-door services even with the use of unregistered lessons are not customized and then spreaded. Orientation as a counseling service is classified as Customized because it is particularly personalized (Fig. 4). 
Figure 4 - Orientation tutoring practices in the Individualization/Personalization Model. [Source: author's own]

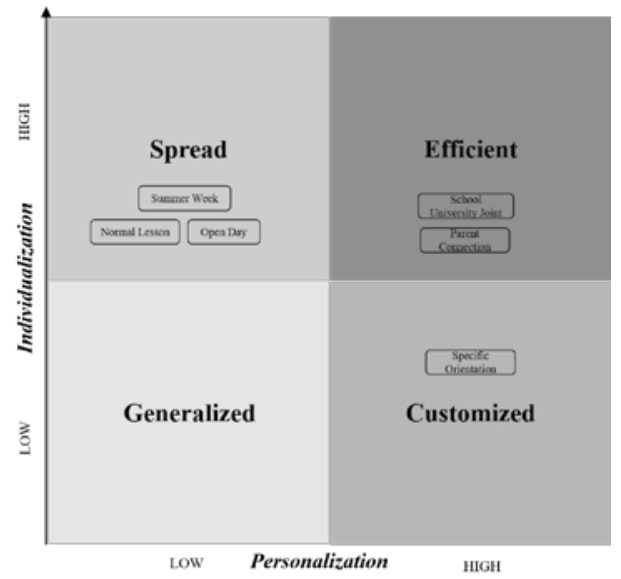

Regarding the tutoring services Group lessons are services that we could rank as Generalized, which are neither personalized nor individualized. On the opposite side, we have peer-tutoring practices and dedicated tutoring. Practices such as tutoring with e-learning and international student services are individualized for the reference category but do not have a particularly relevant personalization nature. Personalization is decisive in services such as psychological counseling and university-specific projects for students with special needs (disabled students, DSA, student workers) (Fig. 5).

Figure 5 - Tutoring practices in the Individualization/Personalization Model. [Source: author's own]

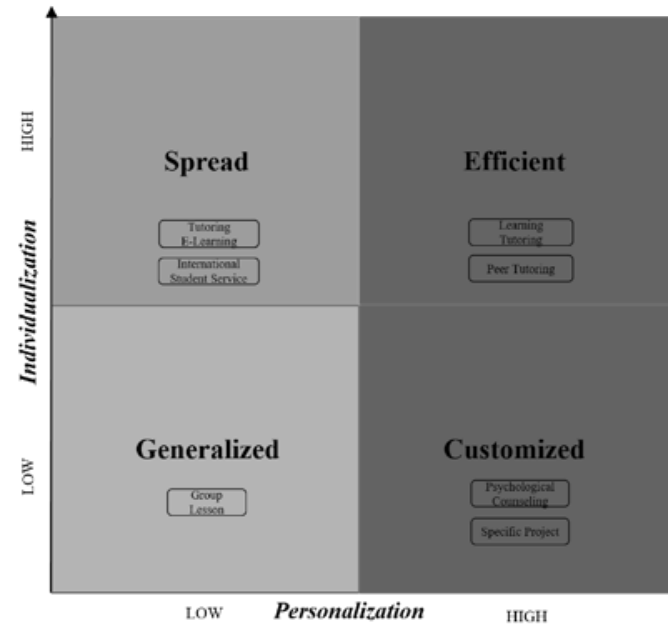


Regarding the outgoing tutoring (career counseling), services such as Job Placement are categorized as Efficient, while Career Day services and Online Platforms for CVs collection having a low relation with single and / or newly graduated students are classified as widespread. Finally, the counseling service aimed at specific professional profiles is a very personalized service, which is therefore defined as Customized (Fig. 6).

Figure 6 - Job Orientation tutoring practices in the Individualization/Personalization Model. [Source: author's own]

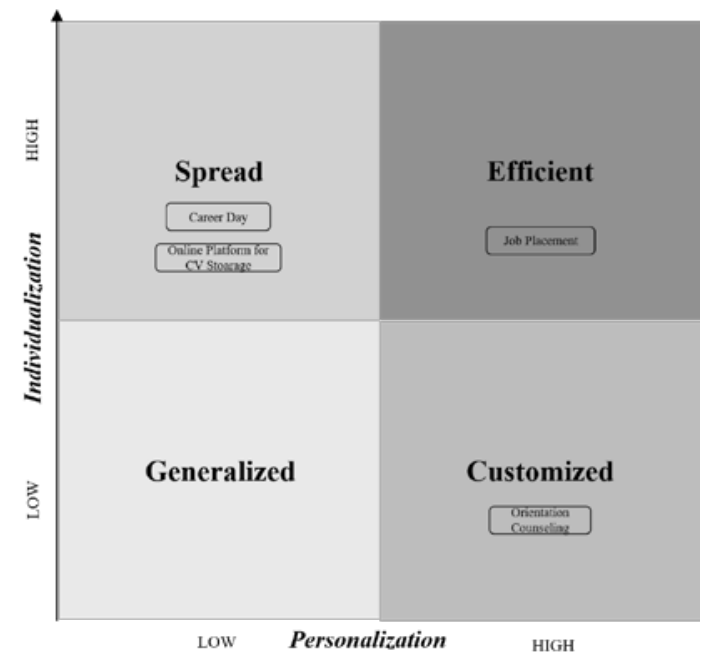

\subsection{Differential peer-tutoring}

Starting from the American university model, a formal distinction is being made between the personal tutor and the professional tutor who accompanies the internship of the students and advises them on choices regarding their professional future and the most effective insertion into workplaces.

Beside the institutional figure of the lecturer there are three figures related to the teaching-learning activity: the 'resident tutor', the 'senior tutor' and the 'junior tutor'.

The Resident tutor is a research specialist or $\mathrm{PhD}$ directly involved in teaching and coordinating the course activities, especially supporting the doctoral and master dissertations.

The senior tutor, graduate and expert in the subject, has the role of managing the integrative teaching and co-ordination of the junior tutor's study assistance services.

The junior tutor was a degree student able to assist younger students in their learning path during study sessions, exercise activities and labs. 
The interesting news is that the training course is articulated from the entrance of the student enrolled as a succession of tutorial relationships (teacher-tutor, resident tutor, senior tutor and junior tutor) in which each intermediate figure is simultaneously the object and subject of the tutorial relationship in a training responsibility that comes to involve the students themselves. The students actively co-operate in the learning of the younger students, in the extent and within the limits of their specific skills.

The peer-tutoring practices are present in 7 of 18 universities. In this field, some of the services of excellence are evident: among them the presence of tutor students (with annual contracts), the 'Pact with the Student', systematic practices of peer-tutoring both in presence and online, the group-tutor in peer tutoring practices; the excellenceoriented tutor and the formalization of the presence of the Junior $\mathrm{Tu}-$ tor, both a research fellow or a PhD student.

Following the American university analysed-for-the-research model, the tutoring center for excellence is a tutoring course aimed at the development of cross-disciplinary and transversal skills. Its activity resides in particular in:

- linguistic tutoring

- coupled linguistic tutoring

- informatic tutoring

Below is the timeline of the services offered to students since their entrance in the university (Fig. 7).

Figure 7 - Timeline of Tutoring practices from school to job. [Source: author's own]

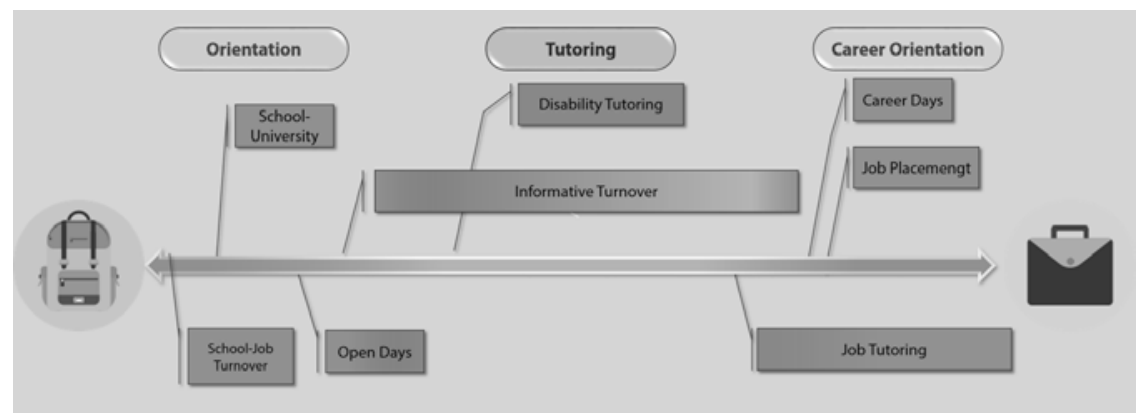

\section{Final remarks}

Starting from a real problem, perceived as an organizational problem, the comparative analysis of tutoring practices described aimed at differentiating practices depending on the training moment in which 
they are located. The analysis allowed to distinguish between supportive and empowering approach. Based on the practices of excellence identified in the analysis of national and international models, proposals for professional tutoring practices are advanced for both tools and procedures, such as tutoring practices through badge and e-portfolio, longitudinal tutoring practices, coupled tutoring and work-oriented tutoring practices.

Practice-based practices are mostly focused on individual student's needs, are individual-based practices aimed at filling in formative and informational gaps, reducing student learning load, or facilitating access to university bureaucratic maze. What is and what does a supportive tutor is still overly a heteronomous concept, while the empowering tutoring is aimed at creating learning platforms for soft-skills and for the professional skills that are useful and attractive in the labor market.

The need to tie more and more what is being studied with what is going to make in the work market, presents the need to bring students into the employability criteria that are validated in the professional worlds. For this reason, comparison with the models of didactic innovation and the practices of foreing universities allows the openness to forms of tutoring of excellence where the interest is in supporting the learner in the process of acquiring entrepreneurial and managerial connotations.

Tandem tutoring also allows conceptualizing students participation in university life and their progression of academic careers as collaborative relationships that characterize potential development areas and collaborative research.

The modeling proposal did not drive to the transformation-implementation of new teaching practices, but was more connected with the purpose of understanding tutorship impact on the negotiation of change processes.

Tutoring practices become objects that are being constructed, negotiated and shared, which can not be defined from beginning because their plausibility and applicability criteria are right in the ability to be able to converse with situations and to be situated in local organizational contexts.

The tutoring becomes one of the 'didactic management' activities (Paparella 2009: 23), towards students, particularly in the following areas:

a. Promotion and Incoming Information [...]

b. Ongoing consulting for the university careers [...]

c. Integrative business management $[\ldots]$

d. Detection of levels of satisfaction [...]

e. Cultivating employability and outgoing job orientation [...]

f. Managing special educational needs [...] (Paparella 2009: 23-24). 
Instead of attempting to implement action models extracted from other realities and imposed, a process of negotiation between two objects - the tutoring practices situated in place and the tutoring practices of other universities - has been opened up. This process could result in a transformative path whose goal is to define shared repositories to assume them as common commitments by a part of the department community.

\section{References}

Álvarez P., González M. 2008, Los planes de tutoría en la Universidad: una guía para su implantación, Servicio de Publicaciones de La Universidad de la Laguna, San Cristóbal de la Laguna.

Boffo V., Fedeli M., Lo Presti F., Melacarne C. and Vianello M. 2017, Teaching and learning for employability. New strategies in higher education, Pearson, Milano.

Boffo V., Federighi, P. and Torlone F. (eds.) 2015, Educational Jobs: Youth and Employability in the Social Economy, Firenze University Press, Firenze.

Coriat M. and Sanz R. (ed.) 2005, Orientación y Tutoría en la Universidad de Granada. Granada, Editorial Universidad de Granada, Granada.

Da Re L., Álvarez P.R. and Clerici R. 2016, Le attività e gli strumenti del programma di Tutorato Formativo per i nuovi iscritti all'università: una guida operativa, Rapporto Tecnico.

Fabbri L. 2007, Comunità di pratiche e apprendimento riflessivo, Carocci, Roma.

Fabbri L. and Melacarne C. 2016, Didattica dell'innovazione e innovazione didattica. L'apprendimento come condizione per il cambiamento, in Fedeli M., Grion, V. and Frison D. (eds.) Coinvolgere per apprendere. Metodi e tecniche partecipative per la formazione, Pensa MultiMedia, Lecce, 319-339.

Giuliani A., Moretti G. and Morini A. 2016, Didactic tutoring services and obligations for additional learning,, an empirical exploratory research: the case of the Department of Educational Science at Roma Tre University, «Italian Journal of Educational Research", 15, 63-78.

Mezirow J. 2003, Apprendimento e trasformazione, Raffaello Cortina, Milano.

Paparella N. (ed.) 2009, Il progetto educativo, vol. III, Armando Editore, Roma.

Topping K., Duran D. and Van Keer H. 2015, Using peer tutoring to improve reading skills: a practical guide for teachers, Routledge, London.

Wenger E., McDermott R. and Snyder W.M. 2007, Coltivare comunità di pratiche. Prospettive ed esperienze di gestione della conoscenza, Guerini e Associati, Milano.

Zabalza M. 2003, Competencias docentes del profesorado universitario: calidad y desarrollo profesional, Narcea, Milano. 